\title{
Improved climatic chamber for desiccation simulation
}

\author{
Catalina Lozada ${ }^{1, a}$, Bernardo Caicedo ${ }^{1}$ and Luc Thorel ${ }^{2}$ \\ ${ }^{1}$ Civil and Environmental Department, Universidad de Los Andes, Cr 1 \#18A-12 Bogotá, Colombia \\ ${ }^{2}$ LUNAM Univ. IFSTTAR, GERS, Geomaterials and Modeling in Geotechnics Lab.44340 Bouguenais, France
}

\begin{abstract}
The climatic chamber at the Universidad de Los Andes was improved for modeling desiccation in soil layers. This chamber allows the measurement of different environmental variables. In this research, evaporation tests were conducted in water imposing boundary conditions for drying, and then these tests were performed in a soil layer. The soil was prepared from a slurry state and was drying controlling the temperature, the infrared radiation, the wind velocity, and the relative humidity. In the first part of this paper, a description of the climatic chamber, operation ranges and theoretical work principles of the climatic chamber are presented. Then, the second part shows the results for desiccation in water and soil. The desiccation tests performed with the climatic chamber allow simulating all environmental conditions accurately during drying coupling the effect of all environmental variables. As a result, the evaporation rate increases with infrared radiation in soil and water. The rate at the beginning of the desiccation tests in clays is the same as in water. However, this evaporation rate decreases as the soil becomes desiccated.
\end{abstract}

\section{Introduction}

Cracks appear in clay deposits when water evaporates from the surface during dry seasons. The saturation degree decreases with time and soil shrinks producing cracks. Many authors have investigated the formation of these cracks; principally, these studies deal with experimental tests of cracking process controlling environmental conditions [1-7]. However, little research has been made in laboratory tests controlling all environmental variables at the same time.

The first version of a climatic chamber was developed at Los Andes University in 2010 [8] for physical modelling applications in centrifuge. This apparatus has shown possibilities of controlling some atmospheric variables but also had limitations on power. This second chamber is an improved version of the first one ; it can simulate adequately soil desiccation and was used for modelling the evolution of cracks in a thin layer of clay controlling all environmental variables.

The climatic chamber has different subsystems allowing the control of temperature, relative humidity, solar radiation, and wind velocity independently.

This paper presents three main items: (i) the characteristics of the climatic chamber of the Universidad de Los Andes; (ii) preliminary results of potential evaporation of water; (iii) preliminary tests of drying in clayey soil.

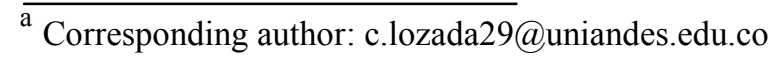

\section{The climatic chamber for modelling soil desiccation}

A new climatic chamber was designed to perform desiccation tests in clayey soil. This chamber has different subsystems allowing the air to follow a particular thermodynamic path through a close circuit (Fig. 1). The subsystems, included in the climatic chamber, are described in next items and depicted in Figure 2.

1) Two cold plate coolers condensate water to obtain a specific relative humidity in the chamber (Fig. 2a). A condensate water reservoir is located following the plates. 2) After the air is cooled, it passes through two air heaters to impose the temperature in the chamber (Fig. 2a).

3) To propel the air from the heaters to the chamber and to simulate wind velocity above the soil samples, a set of six fans were installed (Fig. 2b).

4) After the air passes above the soil sample, it is propelled to the cold plate coolers through a set of four fans (Fig. 2b).

5) Afterwards, the circuit starts again.

\subsection{Instruments of measurement}

As is shown in Figure $2 b$, the adiabatic box, where is located the soil sample, includes a robotic XY module. This module has a set of sensors to measure the environmental variables [8]. Also, temperature and relative humidity are measured before and after air cross through the air heaters (points a and b in Figure 1). The 
list of sensors included in the climatic chamber is shown in Table 1.

Table 1. Specifications of the sensors of the climatic chamber.

\begin{tabular}{|c|c|c|c|}
\hline Quant & Type sensor & $\begin{array}{c}\text { Range / } \\
\text { Precision }\end{array}$ & $\begin{array}{c}\text { Position in } \\
\text { the chamber }\end{array}$ \\
\hline 1 & $\begin{array}{c}\text { IR } \\
\text { temperature }\end{array}$ & $\begin{array}{c}-40-600^{\circ} \mathrm{C} / \\
\pm 2^{\circ} \mathrm{C}\end{array}$ & XY module \\
\hline 1 & $\begin{array}{c}\text { Atm. } \\
\text { pressure }\end{array}$ & $\begin{array}{c}15-115 \mathrm{kPa} / \\
\pm 1.7 \mathrm{kPa}\end{array}$ & $\mathrm{XY}$ module \\
\hline 2 & $\begin{array}{c}\text { Wind } \\
\text { velocity }\end{array}$ & $\begin{array}{c}0-10 \mathrm{~m} / \mathrm{s} / \\
\pm 0.2 \mathrm{~m} / \mathrm{s}\end{array}$ & $\mathrm{XY}$ module \\
\hline 3 & $\begin{array}{c}\text { Relative } \\
\text { humidity }\end{array}$ & $\begin{array}{c}0-100 \% / \\
\pm 3.5 \%\end{array}$ & $\begin{array}{c}\text { (1)XY } \\
\text { module } \\
(2) \text { after and } \\
\text { before heaters }\end{array}$ \\
\hline 3 & $\begin{array}{c}\text { Temperature } \\
\text { RTD }\end{array}$ & $\begin{array}{c}-200-800^{\circ} \mathrm{C} \\
/ \pm 0.1^{\circ} \mathrm{C}\end{array}$ & $\begin{array}{c}\text { module } \\
(2) \text { after and } \\
\text { before heaters }\end{array}$ \\
\hline \multirow{2}{*}{1} & $\begin{array}{c}\text { Laser } \\
\text { displacemen } \\
\mathrm{t}\end{array}$ & $\begin{array}{c}0-50 \mathrm{~mm} / \\
\pm 10 \mu \mathrm{m}\end{array}$ & $\begin{array}{c}\mathrm{XY} \text { module } \\
\end{array}$ \\
\hline
\end{tabular}

\subsection{Sub-systems of the climatic chamber}

\subsubsection{Solar radiation}

Soil and air are additionally heated with two Philips infrared lamps simulating solar radiation. To compare the irradiance spectra of the sun and the lamps, Figure 3 shows the normalized irradiance spectra for the black body temperature of the sun and the lamps. This temperature is $5523 \mathrm{~K}$ of the sun and $2450 \mathrm{~K}$ of the lamps.

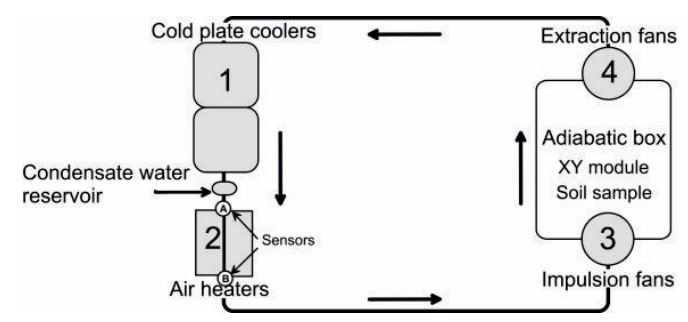

Figure 1: Air circuit in the climatic chamber

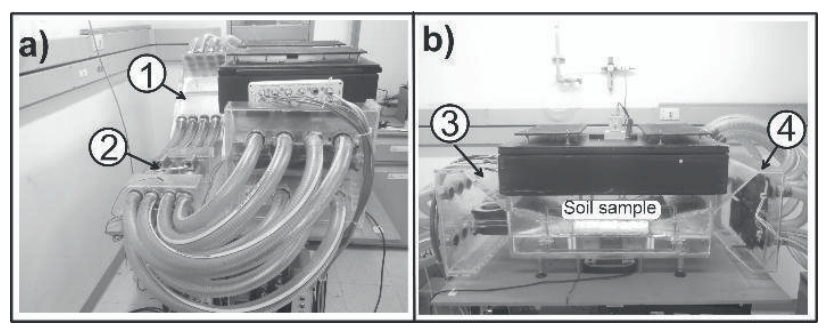

Figure 2: Air conduction components of the climatic chamber. a) Lateral view b) Frontal view.

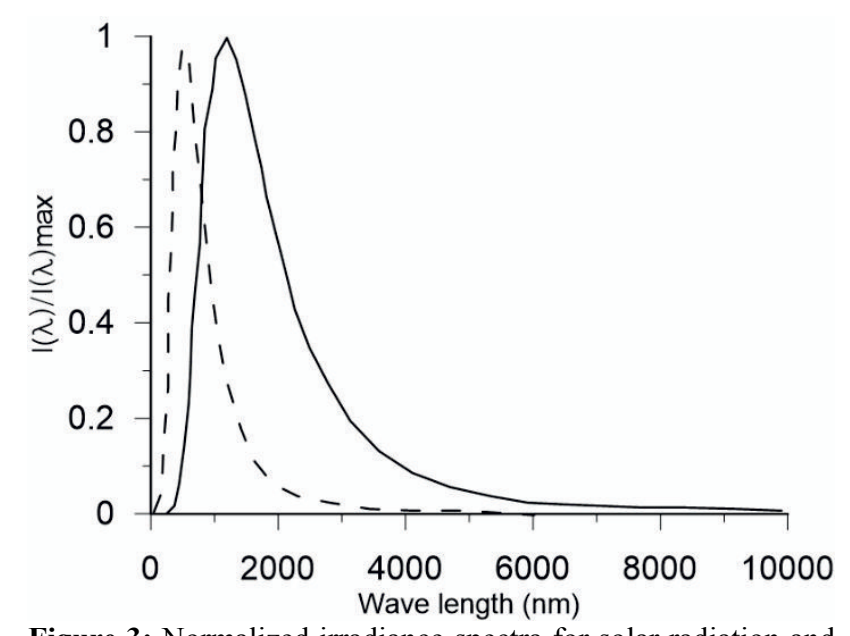

Figure 3: Normalized irradiance spectra for solar radiation and infrared lamps calculated with the Planck's law [8].

The direct infrared radiation $\mathrm{I}_{\mathrm{IR}}$ at the soil surface is calculated with a geometrical relationship for heat exchange by radiation $[8,9]$.

$$
I_{I R}=0.5^{2} \sum_{i=1}^{2} \frac{I_{E(0.5)}(\alpha R)}{r_{R}^{2}}
$$

where $I_{E}(0.5)$ is the emission angle of the lamp at a distance of $0.5 \mathrm{~m}, \alpha \mathrm{R}$ is the emission angle, and $r_{R}$ is the distance between the lamp and the surface of the soil. Figure 4 presents the direct infrared radiation of the two lamps installed in the climatic chamber calculated with the previous equation. The lamps are separated $40 \mathrm{~cm}$, and the distance between the lamps and the surface is $30 \mathrm{~cm}$.

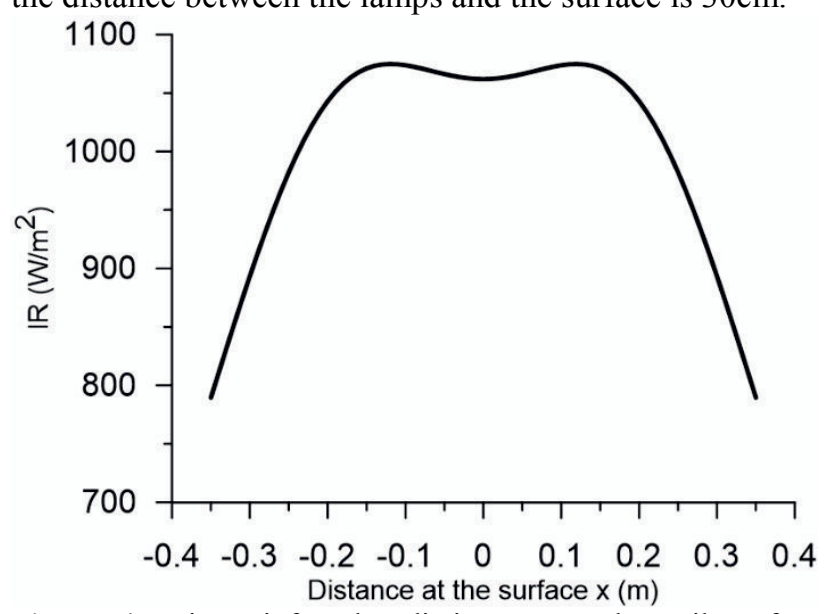

Figure 4: Direct infrared radiation IR at the soil surface calculated for the two infrared lamps

\subsubsection{Wind velocity}

Six fans were installed at the entrance of the adiabatic box to conduct the air above the soil and to simulate the wind velocity. This velocity is measured by the sensor placed in the XY module. The distance between the soil and the sensor is $1.5 \mathrm{~cm}$. The wind velocity was measured at the points A, B, and C (Fig. 5).

These measurements were made varying the power supply of the fans (Fig. 6). During the tests, the extraction fans have a constant power supply of $100 \%$ (Fig. 2b). 


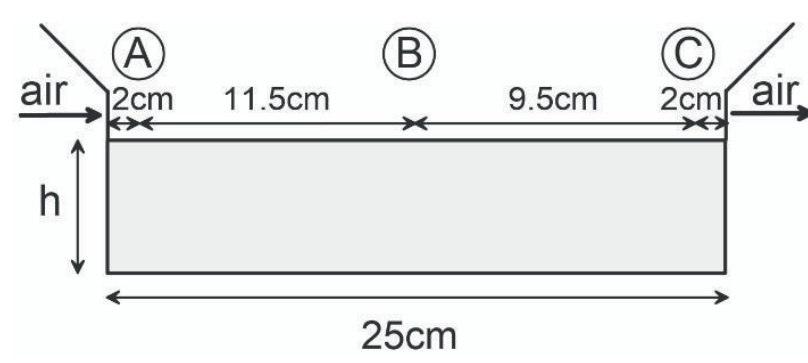

Figure 5: Location of measurements of wind velocity above the soil

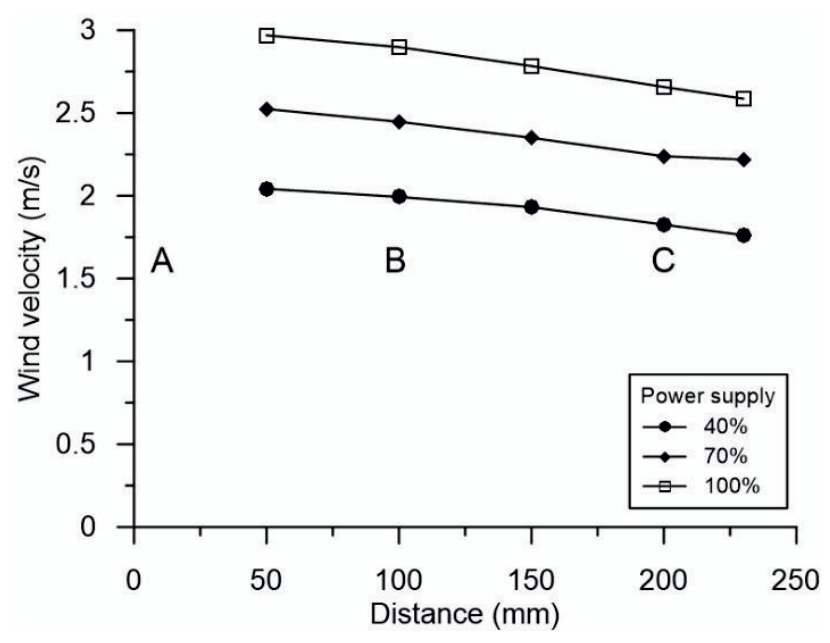

Figure 6: Wind velocity in function of the distance of the soil sample

\subsubsection{Temperature and relative humidity subsystem}

To obtain specific conditions of relative humidity and temperature in the chamber, the temperature of the two cold plate coolers and the temperature of the two heaters is imposed. The temperature of the cold plate coolers allows the water to condensate reaching $100 \%$ of saturation. Therefore, the temperature applied by the cold plate coolers is compared with the theoretical dew point temperature.

The theoretical dew point temperature is calculated by the integration of the Clausius Clayperon equation considering a volume of moist air cooled isobarically [10].

$$
T_{d} \approx T_{c}+\frac{R T_{c}^{2}}{\Delta H_{v} M_{w}} \ln (R H)
$$

where $T_{c}$ is the temperature in the chamber, $R$ is the ideal gas constant, $\Delta H_{v}$ is the latent heat for water evaporation, $M_{w}$ is the molecular weight of water, and $R H$ is the relative humidity in the chamber.

Figure 7 depicts dew point temperatures in function of relative humidity for a temperature of the heaters of $22^{\circ} \mathrm{C}$ and the applied dew point temperature i.e the temperature of the cold plate coolers.
The theoretical values are higher than the applied temperature, in the left part of the curve, because the loss of heat in the chamber. Contrary, the theoretical values are lower at the right of the curve because of the limitations of relative humidity in the laboratory.

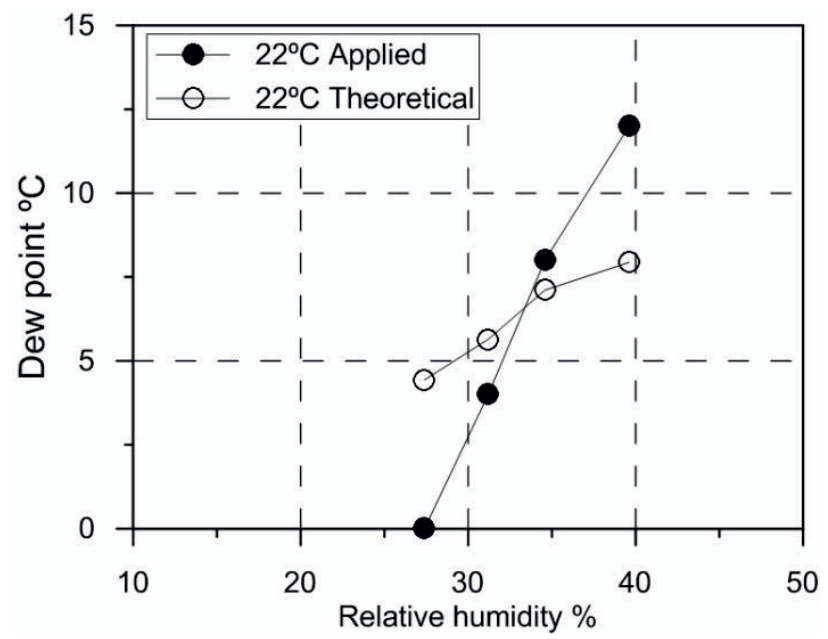

Figure 7: Dew point temperature imposed and theoretical.

Fifteen tests were made varying the temperature of the heaters and the temperature of the cold plate coolers to calibrate the range of conditions of relative humidity and temperature in the climatic chamber. Relative humidity and air temperature were measured in the adiabatic box (Fig. 8a and Fig. 8b). The operation ranges of the chamber for a temperature of the cold plates between 0 and $12{ }^{\circ} \mathrm{C}$ and a temperature of the heaters between $22^{\circ} \mathrm{C}$ to $39^{\circ} \mathrm{C}$ are: relative humidity $[18 \%$ $40 \%]$ and temperature $\left[23^{\circ} \mathrm{C}-38^{\circ} \mathrm{C}\right]$.

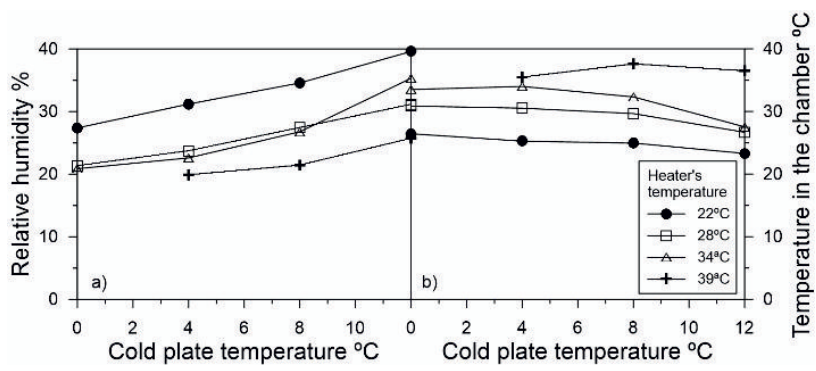

Figure 8: Environmental conditions in the adiabatic box controlling the temperature of the heaters and the cold plate coolers.

\section{Performance of the apparatus}

\subsection{Theoretical working principle}

Fundamental principles of physics regarding evaporation and condensation of water, and heating by radiation and convection have been considered in the design of the climatic chamber [8], Variables of moist air such as: the saturation water vapour pressure, $e w$; the partial vapour pressure, $e$; the relative humidity, $U w$; the dew point temperature $T d$; and the mixing ratio $r$ (relation between the mass of water vapour and the mass of dry air); are 
used to describe the state of vapour in the artificial atmosphere created in the environmental chamber. The Mollier diagram summarizes these different humidity functions in one chart: i.e. the mixing ratio as a function of air temperature.

The thermodynamic cycle applied by the cold plate coolers and heaters used to control relative humidity and temperature is illustrated in Figure 9. This cycle is as follows:

a) Point $\mathrm{C}$ represents the thermo-physical properties of air in its initial state $\mathrm{C}$ in Fig. 9.

b) The temperature of the cold plate coolers is reduced resulting in a decrease of the air temperature and an increase in relative humidity. If cooling continues, the mixing ratio will decrease, and the air will reach the saturation curve. At this point water vapour condenses. The process follows the C-D-E path in Fig. 9.

c) The water condensate is channelled into a container allowing the calculation of the volume.

d) Air heats again when flowing below the heaters, air temperature increase and relative humidity decrease along path E-A in Fig. 8.

e) Finally, path A-B-C in Fig. 8 indicates that when air circulates over the soil its temperature and relative humidity increase or decrease, depending on the properties of the soil at the surface. After this, the cycle starts again.

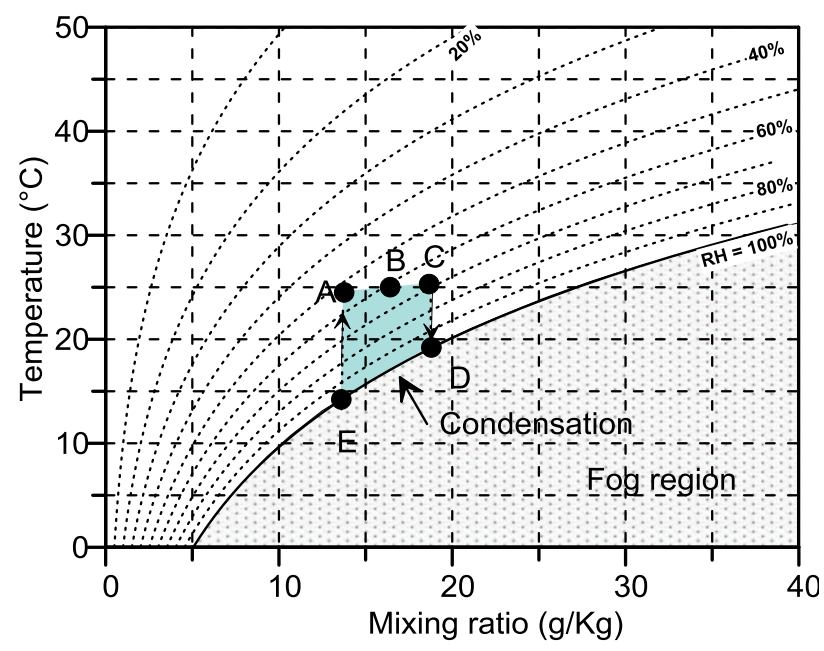

Figure 9: Thermodynamic cycle applied by the cold plate coolers and heaters.

\section{Water evaporation}

To assess the potential evaporation, tests in water were made controlling the conditions of wind velocity, temperature, and relative humidity.

\subsection{Test procedure}

Tests T2 and T3 were conducted to determine the effect of the infrared radiation on the evaporation rate at the same wind velocity and the same initial relative humidity (see Table 2). The test procedure is divided into three parts: (i) environmental conditions were imposed in the climatic chamber without water during 30 minutes.

(ii) $500 \mathrm{~g}$ of water were added to a square glass container and get into the chamber.

(iii) Evaporation tests started, and measurements of relative humidity, temperature, atmospheric pressure, and wind velocity were registered each 15 minutes at the points A, B, C (Fig. 5). Additionally, evaporated water was weighted with an electronic balance.

Table 2 Environmental conditions for evaporation tests in water.

\begin{tabular}{|c|c|c|c|c|}
\hline Test & $\begin{array}{c}\text { Wind } \\
\text { velocity } \\
(\mathbf{m} / \mathbf{s})\end{array}$ & $\begin{array}{c}\text { T heaters } \\
\left({ }^{\circ} \mathbf{C}\right)\end{array}$ & $\begin{array}{c}\text { IR } \\
\left(\mathbf{W} / \mathbf{m}^{2}\right)\end{array}$ & $\begin{array}{c}\text { T Peltier } \\
\left({ }^{\circ} \mathbf{C}\right)\end{array}$ \\
\hline $\mathrm{T} 2$ & 2.75 & 18.5 & 371.7 & 0 \\
\hline $\mathrm{T} 3$ & 2.75 & 18.5 & 0 & 0 \\
\hline
\end{tabular}

\subsection{Experimental results}

Figure 10 shows the thermodynamic cycle for the test T2 and Figure 11 shows the thermodynamic cycle for the test T3.

Point A, B, and C are located above the water surface, and point $\mathrm{E}$ corresponds to the temperature of the cold plate coolers. Additionally, a point D represents a midpoint in the path of the air when passes through the cold plate coolers.

The increase of infrared radiation leads the rise of air temperature and a decrease in relative humidity. For this reason, the thermodynamic cycle expanded as radiation increases (Fig. 11). In this figure, point B presents lower values of temperature. This expansion occurs as Infrared radiation emitted by the lamps is maximum in this position as shown in Figure 4.

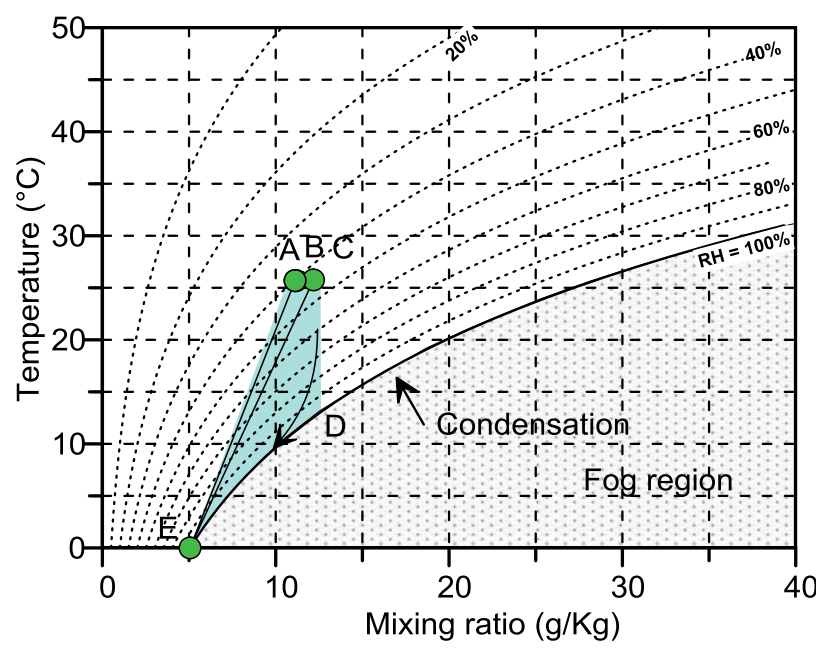

Figure 10: Thermodynamic cycle applied by the cold plate coolers and heaters. Test without infrared radiation. 


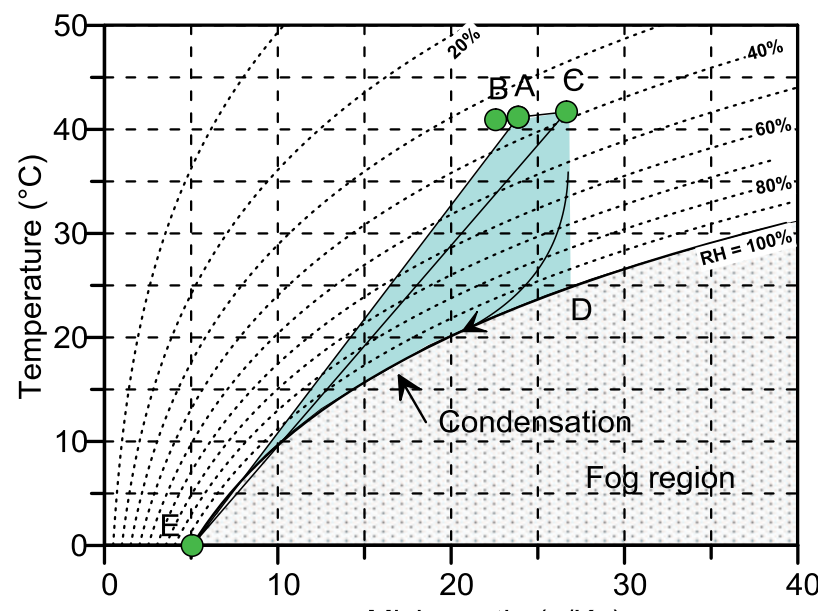

Figure 11: Thermodynamic cycle applied by the cold plate coolers and heaters. Test with infrared radiation.

The evaporation rate of water depends on environmental variables as a whole. As relative humidity decreases and temperature increase with infrared radiation, the capacity to contain water of the simulated atmosphere increase. For that reason evaporation rate is higher for the test T2 than for the test T3 as shown in Figure 12.

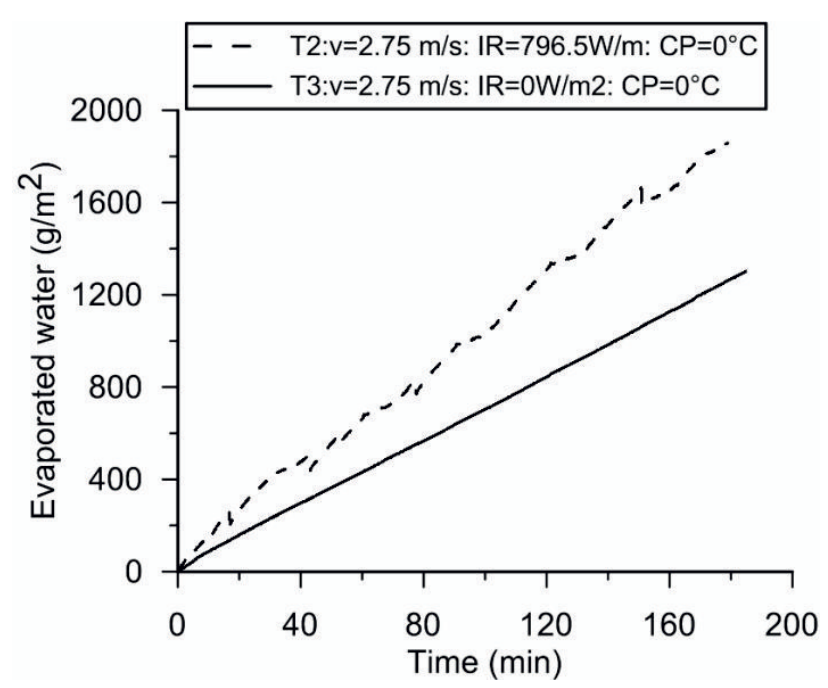

Figure 12: Effect of infrared radiation on evaporated water.

\section{Preliminary tests in clayey soil}

Same tests, T2 and T3, were conducted on clay. The experimental procedure is the same as the tests in water. Additionally, each hour a photo was taken to observe the soil behaviour during evaporation of water.

The soil used in this research is Speswhite kaolin clay and is prepared with a water content of $w=1.5 \mathrm{LL}$. The liquidity limit of the Speswhite clay is $L L=55 \%$, so the initial water content is $w_{\mathrm{o}}=82.5 \%$.

The evaporated water in the tests with clay is shown in Figure 13. At the beginning of the tests, the evaporation rate shows the same value as in the tests conducted with water. However, as the soil is desiccated the evaporation rate decreases until the soil is completely dried.

Figure 14 and Figure 15 show the soil sample at the end of the drying test. It seems that soil contraction is higher in the tests exposed to less severe environmental conditions without cracks evidence.

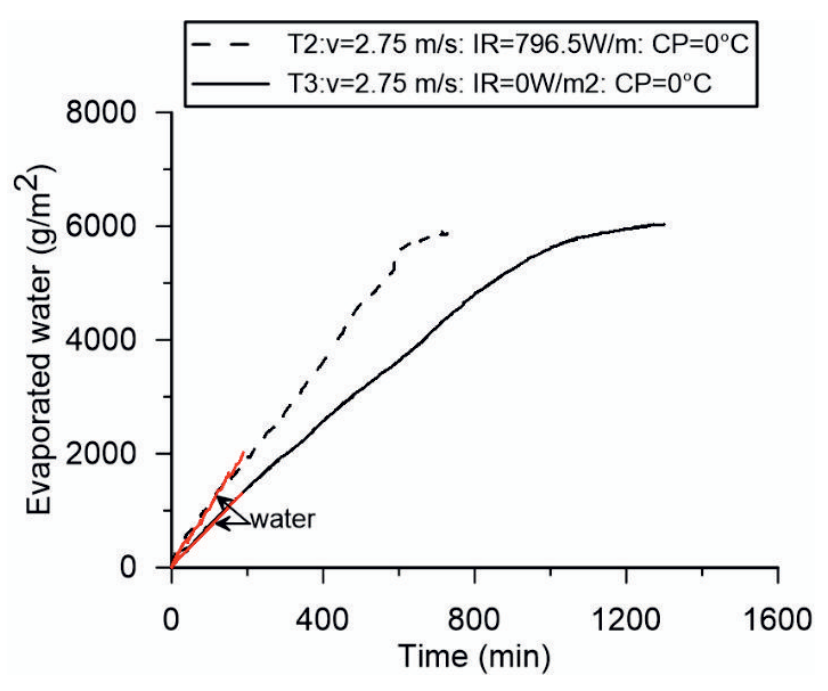

Figure 13: Effect of infrared radiation on evaporated water in clay.

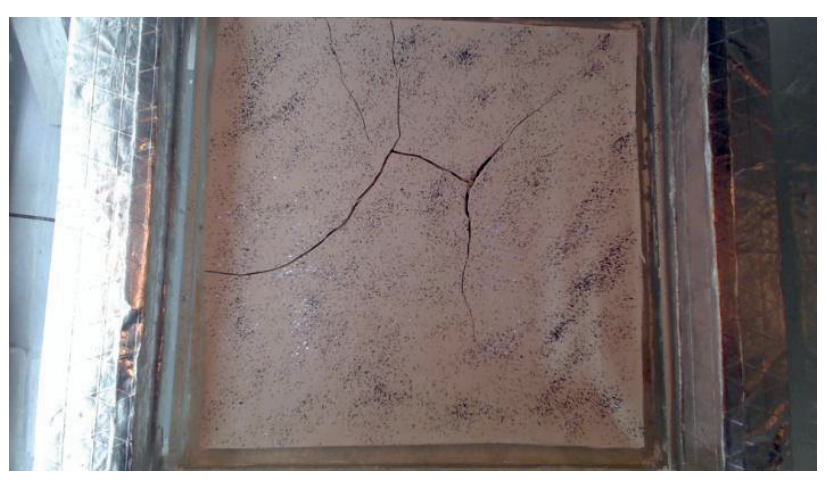

Figure 14: Soil sample at the end of desiccation. Test 2.

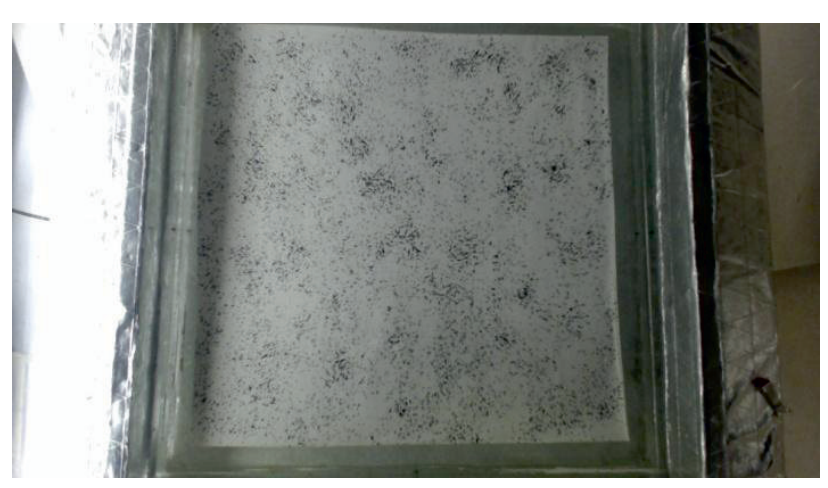

Figure 15: Soil sample at the end of desiccation. Test 3.

\section{Conclusions}

The climatic chamber at the Universidad de Los Andes was redesigned in order to perform desiccation tests in soil layers. This chamber allows the user to impose 
specific environmental conditions through a close circuit of air. Preliminary results of water evaporation lead to state the next conclusions:

1. The main effect of infrared radiation on evaporation is the decrease of relative humidity in the air and the increase of air temperature. These conditions, and the increase of water temperature allow the increase of the evaporation rate.

2. The evaporation rate in soil is the same as water at the beginning of the test. As desiccation occurred, evaporation rate decreases.

This device will be used in the future to conduct parametric study on the evaporation phenomenon in coupled environmental condition (humidity, temperature, wind, infrared radiation).

\section{References}

1. A. Corte, \& A. Higashi, No. CRREL-RR-66 Final Rpt. 5. (1964).

2. C. J. Miller, H. Mi, \& N. Yesiller, J. Am. Water Resour. Assoc. 677-686 (1998).

3. P. C. Prat, A. Ledesma, \& M. R. Lakshmikantha, In Fracture of Nano and Engineering Materials and Structures. 1373-1374. (2006).

4. H. Nahlawi, \& J. K. Kodikara, Geotech. Geol. Eng., 24, 6. 1641-1664. (2006).

5. M. R. Lakshmikantha, P. C. Prat, \& A. Ledesma, Geotech. Test. J. 32(6), 505-51 (2009).

6. C. S. Tang, Y. J. Cui, A. M. Tang, \& B. Shi, Eng. Geol.114, 3, 261-266. (2010).

7. C. S. Tang, B. Shi, C. Liu, W. B. Suo, \& , L. Gao, Appl Clay Sci, 52, 1, 69-77. (2011).

8. J. Tristancho, B. Caicedo, L. Thorel, \& N. Obregon, Geotech. Test. J. 35, 1, 159-171. (2012)

9. F. Kreith, R. Manglik, \& M. Bohn, Principles of heat transfer. (2010)

10. J. H. Seinfeld, \& S. N. Pandis, Atmospheric chemistry and physics: from air pollution to climate change. (2012). 